\title{
Jumping performance in the highly aquatic frog, Xenopus tropicalis: sex-specific relationships between morphology and performance
}

Frogs are characterized by a morphology that has been suggested to be related to their unique jumping specialization. Yet, the functional demands associated with jumping and swimming may not be that different as suggested by studies with semi-aquatic frogs. Here, we explore whether features previously identified as indicative of good burst swimming performance also predict jumping performance in a highly aquatic frog, Xenopus tropicalis. Moreover, we test whether the morphological determinants of jumping performance are similar in the two sexes and whether jumping performance differs in the two sexes. Finally we test whether jumping capacity is positively associated with burst swimming and terrestrial endurance capacity in both sexes. Our results show sex-specific differences in jumping performance when correcting for differences in body size. Moreover, the features determining jumping performance are different in the two sexes. Finally, the relationships between different performance traits are sex-dependent as well with females, but not males, showing a trade-off between peak jumping force and the time jumped to exhaustion. This suggests that different selective pressures operate on the two sexes, with females being subjected to constraints on locomotion due to their greater body mass and investment in reproductive capacity. In contrast, males appear to invest more in locomotor capacity giving them higher performance for a given body size compared to females. 
1 Jumping performance in the highly aquatic frog, Xenopus tropicalis: sex-

2 specific relationships between morphology and performance.

3 Anthony Herrel ${ }^{1,2}$, Menelia Vasilopoulou-Kampitsi ${ }^{1}$ and Camille Bonneaud ${ }^{3}$

4 1. UMR 7179 C.N.R.S/M.N.H.N., Département d'Ecologie et de Gestion de la

5 Biodiversité, 57 rue Cuvier, Case postale 55, 75231, Paris Cedex 5, France.

6 2. Ghent University, Evolutionary Morphology of Vertebrates, K.L. Ledeganckstraat

7 35, B-9000 Gent, Belgium.

8 3. Centre for Ecology \& Conservation, College of Life and Environmental Sciences,

9 University of Exeter, Penryn, Cornwall, TR10 9EZ, U.K.

10 \# pages: 14

11 \# figures: 4

12 \# tables: 2

13 Running title: jumping in an aquatic frog.

14 Address for correspondence:

15 Anthony Herrel

16 Département d'Ecologie et de Gestion de la Biodiversité,

1757 rue Cuvier, phone : $++33-140798120$

18 Case postale 55, 75231, fax : $++33-140793773$

19 Paris Cedex 5, France.

E-mail :

20 anthony.herrel@mnhn.fr 


\section{Summary}


22 Frogs are characterized by a morphology that has been suggested to be related to

23 their unique jumping specialization. Yet, the functional demands associated with

24 jumping and swimming may not be that different as suggested by studies with semi-

25 aquatic frogs. Here, we explore whether features previously identified as indicative

26 of good burst swimming performance also predict jumping performance in a highly

27 aquatic frog, Xenopus tropicalis. Moreover, we test whether the morphological

28 determinants of jumping performance are similar in the two sexes and whether

29 jumping performance differs in the two sexes. Finally we test whether jumping

30 capacity is positively associated with burst swimming and terrestrial endurance

31 capacity in both sexes. Our results show sex-specific differences in jumping

32 performance when correcting for differences in body size. Moreover, the features

33 determining jumping performance are different in the two sexes. Finally, the

34 relationships between different performance traits are sex-dependent as well with

35 females, but not males, showing a trade-off between peak jumping force and the

36 time jumped to exhaustion. This suggests that different selective pressures operate

37 on the two sexes, with females being subjected to constraints on locomotion due to

38 their greater body mass and investment in reproductive capacity. In contrast, males

39 appear to invest more in locomotor capacity giving them higher performance for a

40 given body size compared to females. Introduction

41 Frogs are characterized by a morphology that includes elongated ilia, a shortening of

42 the presacral vertebral series, the fusion of the caudal vertebral elements into an

43 urostyle, and the presence of mobile ilio-sacral and sacro-urostylic joints. These

44 features have been suggested to be related to their unique jumping specialization

45 that originated early-on in their evolutionary history (Shubin \& Jenkins, 1995). The

46 mobility of the ilio-sacral and sacro-urostylic joints is thought to be a key feature for

47 jumping as it allows an extension of the body and thus the transfer of propulsive

48 forces by the coccygeo-iliacus muscles. In specialized aquatic frogs, on the other

49 hand, the ilio-scaral joint is also mobile but highly modified. In Xenopus frogs this

50 joint allows sliding of the ilia along the sacral vertebra which is thought to aid in

51 propulsion (Palmer, 1960; Videler \& Jorna, 1985). Given the radical differences in the

52 ilio-sacral anatomy in specialized swimmers versus jumpers, specialized aquatic

53 frogs are consequently thought to be rather poor jumpers (Olson \& Marsh, 1998).

54 This idea is also supported by broad comparative analyses of jumping performance

55 in frogs where semi-aquatic frogs typically show intermediate levels of performance

56 (Zug, 1972; 1978; Gomes et al., 2009). 
57 However, despite the anatomical differences in the ilio-sacral joint between

58 specialized aquatic species and terrestrial jumpers, the functional demands associated with jumping and swimming may not be that different. For example, in semi-aquatic frogs, no trade-offs between swimming and jumping capacity could be demonstrated, suggesting that no direct design conflict is present in animals performing both types of locomotion on a daily basis (Nauwelaerts, Ramsay \& Aerts, 2007). Moreover, different anatomical traits explained swimming versus jumping performance in these semi-aquatic frogs which may explain the absence of a correlation between the two performance measures. However, given the role of elastic energy storage in the plantaris longus tendon in determining jumping performance (Astley \& Roberts, 2011), aquatic frogs with shorter plantaris tendons may need to invest in greater absolute muscle cross sectional areas to achieve high levels of jumping performance. As such, the traits that determine jumping and swimming may be more similar in specialized aquatic frogs compared to semiaquatic species.

Here, we build upon an existing data set on locomotor performance in the specialized aquatic frog, Xenopus (Silurana) tropicalis (Herrel \& Bonneaud, 2012a,b), to explore whether trade-offs exist between swimming and jumping and whether similar morphological traits are the best predictors of the two performance traits. Based on the results of Nauwelaerts and co-workers (2007), we predict that different anatomical features will determine the two performance traits resulting in the absence of a correlation between both. Moreover, we predict that jumping performance should be correlated to overall exertion capacity, as the energetics of jumping likely limit the number of jumps rather than the overall distance jumped per se. Thus the distance jumped to exhaustion should thus be positively correlated to jumping performance. However, a greater proportion of fast glycolytic muscle fibers in the muscles responsible for jumping may cause animals to fatigue quicker (James, Navas \& Herrel, 2007) and as such may in theory cause a trade-off between jump force and the distance jumped to exhaustion.

We also test whether jumping performance differs between the two sexes and whether the morphological determinants of jumping performance are similar in the two sexes. Given that $X$. tropicalis frogs are dimorphic in body mass and limb dimensions, with females being heavier but males having relatively longer limbs 
92 reproductive output than males in many animals, including frogs (Shine, 1979).

93 Thus, females are often bigger and heavier than males in species where males do

94 not engage in male-male combat (Schauble, 2004). Moreover, most of the extra

95 body mass is involved in reproductive output, thus increasing the load relative to the

96 available muscle mass and cross sectional area. Finally, given that the sexes are

97 known to differ in swimming performance and endurance capacity (Herrel \&

98 Bonneaud, 2012a), we also explore sex-specific correlations between the different

99 locomotor performance traits.

\section{Materials and methods}

\section{Animals}

102 Xenopus tropicalis were caught in the wild in December 2009 in Cameroon brought

103 back to France and housed at the Station d'Ecologie Experimentale du CNRS at

104 Moulis. Animals were housed in groups of 8-10 individuals in aquaria $(60 \times 30 \times 30$

$105 \mathrm{~cm}$ ) with the temperature set at $24{ }^{\circ} \mathrm{C}$ which is assumed to be close to the preferred

106 and optimal temperature of Xenopus frogs (Casterlin \& Reynolds, 1980; Miller,

107 1982), and similar to water temperatures measured in the field in ponds where the

108 animals were caught $\left(22-26^{\circ} \mathrm{C}\right.$; Careau et al., 2014). Frogs were fed every other day

109 with beef heart, earthworms, or mosquito larvae ad libitum. All individuals were

110 given one month to recover and were then pit-tagged (NONATEC) before the onset

111 of the experiments allowing unambiguous identification. A total of 125 individuals

112 were included in the performance testing. All experiments were approved by the

113 Institutional ethics committee at the MNHN (\#68-25).

114 Morphometrics

115 All animals ( $N=125 ; 56$ males and 69 females) were weighed (Ohaus, precision \pm

$1160.01 \mathrm{~g}$ ) and measured using digital calipers (Mitutoyo, $\pm 0.01 \mathrm{~mm}$ ). The following

117 body dimensions were quantified: body length as the straight-line distance from the

118 cloaca to the tip of the snout, the length of the femur, the tibia, the foot, the longest

119 toe, the ilium and the width across the top of the two ilia (see Herrel et al., 2012).

120 Performance

121 All performance traits were measured at $24^{\circ} \mathrm{C}$. Before the onset of performance

122 measurements, animals were placed for one hour in an incubator set at $24^{\circ} \mathrm{C}$ in

123 individual containers with some water. All performance measurements were 
124 repeated three times over the course of one day for each individual with an inter-

125 trial interval of at least one hour during which animals were returned to the

126 incubator and allowed to rest. At the end of the performance trials animals were

127 weighed, their pit tag numbers recorded and they were returned to their home

128 aquaria and fed. Animals were given at least one week rest between the different

129 performance measures.

130 Data on maximal exertion capacity and swimming performance were taken from

131 Herrel \& Bonneaud (2012a). Repeatabilities of these traits are listed in Careau et al.

132 (2014). In brief, maximal exertion capacity was measured by chasing each individual

133 down a 3 meter long circular track until exhaustion, indicated by unwillingness to

134 move any further when touched and the lack of a righting response (inability to turn

135 when animals are placed on their backs). Burst performance capacity was quantified

136 by measuring maximal instantaneous swimming speed and acceleration of animals

137 filmed with a Redlake MotionPro high speed camera set at $500 \mathrm{~Hz}$.

138 Maximal jump forces were measured using a piezo-electric force platform (Kistler

139 Squirrel force plate, $0.1 \mathrm{~N})$. The force platform (20 by $10 \mathrm{~cm}$ ) was connected to a

140 charge amplifier (Kistler Charge Amplifier type 9865) and forces were recorded at

$141500 \mathrm{~Hz}$, transferred to the computer, and recorded using Bioware software (Kistler).

142 Frogs were placed on the force plate, allowed to rest for a few seconds and then

143 induced to jump by unexpectedly clapping our hands behind the frogs. This elicited

144 maximal escape responses from the individuals causing them to jump as far as

145 possible away from the observer. Frogs were caught and placed back on the force

146 plate as many times as possible during the 60 second recording time. Three jump

147 sessions with three to five jumps each on average were recorded and the single

148 most forceful jump was retained out of all jumps recorded and used for further

149 analyses. Forces in $\mathrm{X}, \mathrm{Y}$ and Z-directions were extracted using the Kistler Bioware

150 software and the total resultant force ( $F_{\text {res: }}$ : vector sum of the $X, Y$ and $Z$ forces) as

151 well as the force in the vertical $\left(Z ; F_{Z}\right)$ and horizontal $\left(X+Y ; F_{X Y}\right)$ planes were

152 calculated. Note that as the position of the frog on the force plate was random (i.e.

153 as preferred by the animal), $X$ - and $Y$ - forces do not represent the fore-aft and medio-

154 lateral forces per se. Thus in one jump the $X$ may be aligned with the direction of

155 jumping and in another the $Y$ or neither. Jump forces were repeatable across trials

156 (intra-class correlation coefficients $F_{\mathrm{z}}: r=0.826, P<0.001 ; \mathrm{F}_{\mathrm{XY}}: r=0.637, P<$

$1570.001 ; \mathrm{F}_{\text {res }}: r=0.814, P<0.001$ ). 
158 Analyses

159 All data were $\log _{10}$-transformed before analyses to fulfill assumptions of normality

160 and homoscedascity. First, we ran analyses of variance to test for differences in jump

161 force between the two sexes. Given that females are larger and heavier than males

162 we also ran analyses of covariance with body mass and hind limb length as

163 covariates. Next, we ran stepwise multiple regressions to explore which

164 morphological traits (SVL, mass, limb segment lengths, total hind limb length)

165 determined variation in jumping force for all individuals as well as for both sexes

166 separately. Finally, we ran Pearson correlations between all morphological traits and

167 jump forces (Table 1 ) and between the forces the different performance traits (Table

168 2) to test for the presence of potential trade-offs between performance traits, again

169 for the entire data set as well as for both sexes separately. All analyses were

170 performed using SPSS v. 15.0.

\section{Results}

172 Peak forces ranged from $0.113 \mathrm{~N}$ in an animal of $35.5 \mathrm{~mm}$ and $4.72 \mathrm{~g}$ to $1.69 \mathrm{~N}$

173 resultant force recorded for an animal of $48.5 \mathrm{~mm}$ and $10.7 \mathrm{~g}$. Thus frogs produced

174 between ten and 20 times their own body mass in jump force. The mean resultant

175 jump force was $0.53 \pm 0.26 \mathrm{~N}$ for an average body length of $38.74 \pm 6.09 \mathrm{~mm}$ and

176 an average mass of $6.37 \pm 2.85 \mathrm{~g}$. Peak vertical forces (0.076 to $1.52 \mathrm{~N}$ ) were

177 greater than forces in the horizontal plane $(0.02-1.22 \mathrm{~N})$.

178 Sexual dimorphism in jump forces

179 Analyses of variance testing for differences in jump force between males and

180 females detected no differences in peak resultant force $\left(F_{1,123}=0.02 ; P=0.89\right)$,

181 peak vertical force $\left(F_{1,123}=0.017 ; P=0.90\right)$, nor peak horizontal force $\left(F_{1,123}=3.46\right.$;

$182 P=0.07)$. However, when taking into account hind limb length significant

183 differences in peak resultant force $\left(F_{1,122}=4.14 ; P=0.044\right)$ and peak vertical force

$184\left(F_{1,122}=5.91 ; P=0.016\right)$ were detected with males producing higher forces for a

185 given hind limb length. Similarly, when using body mass as a covariate, significant

186 differences in peak resultant force $\left(F_{1,122}=13.08 ; P<0.001\right)$ and peak vertical force

$187\left(F_{1,122}=16.94 ; P<0.001\right)$ were observed with males again showing higher forces

188 than females for a given body mass.

189

Morphology performance correlates 
190 Raw correlations between morphological variables and jump forces are given in

191 Table 1. A stepwise regression analyses with the peak resultant force as the

192 dependent variable and the different morphological traits as independents for the

193 whole data set resulted in a highly significant model with hind limb length as the

194 only variable $\left(R^{2}=0.38 ; P<0.001\right)$. A similar analyses run on the data for males

195 only retained a model with ilium length and the length of the longest toe as

196 explicatory variables $\left(R^{2}=0.29 ; P<0.001\right)$. Partial standardized regression

197 coefficients indicated that whereas ilium length was positively associated with peak

198 jump force $(\beta=0.70)$, toe length was negatively correlated $(\beta=-0.35)$ with peak

199 jump force. For females a model with only hind limb length was retained $\left(R^{2}=0.51\right.$;

$200 P<0.001)$. Peak vertical forces $(Z)$ were best predicted by tibia length $\left(R^{2}=0.40 ; P\right.$

$201<0.001)$ for the entire data set, by ilium length and toe length for males $\left(R^{2}=0.31\right.$;

$202 P<0.001$; ilium length $\beta=0.72$; toe length $\beta=-0.34$ ), and by body mass in females

$203\left(R^{2}=0.52 ; P<0.001\right)$. Peak force in the horizontal plane, on the other hand, were

204 best predicted by foot length for the overall data set $\left(R^{2}=0.26 ; P<0.001\right)$, by ilium

205 width in males $\left(R^{2}=0.15 ; P=0.003\right)$, and by foot length in females $\left(R^{2}=0.32 ; P<\right.$

206 0.001).

207 Performance relationships

208 When considering the overall data set significant positive relationships were

209 detected between peak resultant force, peak vertical force and peak horizontal force

210 and the distance jumped to exhaustion (Table 2). Moreover, the peak horizontal

211 forces were positively correlated with the peak swimming velocity (Table 2 ). When

212 analyzing data for males only, the peak resultant force and the peak vertical force

213 were correlated to the distance jumped to exhaustion (Table 2). In females, the peak

214 resultant force, the peak vertical force and the peak horizontal force were positively

215 correlated to the distance jumped to exhaustion (Table 2). Moreover, the peak

216 resultant and vertical forces were negatively correlated to the time jumped until

217 exhaustion (Table 2). Finally, the peak horizontal force was also positively correlated

218 to the peak swimming velocity (Table 2 ).

219 Discussion

220 Sexual dimorphism in jump forces

221 Although absolute jump forces did not differ between the two sexes, a sexual

222 dimorphism in performance became apparent when correcting for known differences 
223 between the sexes in hind limb length or body mass (Herrel et al., 2012). Indeed,

224 when taking into account differences in morphology, males showed higher jump

225 forces than females. This result mimics the observation that males also have a

226 higher endurance capacity in terms of the distance jumped to exhaustion compared

227 to females (Herrel et al., 2012). Given that peak jump forces are correlated to the

228 distance jumped to exhaustion, this makes intuitive sense. Although males are

229 smaller than females, they have relatively longer hind limbs than females (Herrel et

230 al., 2012). Given that hind limb length is correlated to jump force, this explains at

231 least in part while males have a greater relative jumping performance. However,

232 even when correcting for differences in hind limb length, males still have a greater

233 jump forces than females. This suggests intrinsic sex-differences, with males

234 investing more in skeletal muscle tissue and females more in reproductive output.

235 This is confirmed by our analyses indicating that males also have a greater jumping

236 performance when correcting for differences in body mass. Males of $X$. tropicalis

237 typically show high levels of exploration behavior (Videlier et al., in press) and thus,

238 locomotor capacity may be under strong selection. Whether females explore their

239 environment less than males, however, remains to be tested. If females should

240 indeed be more stationary, then this would explain their lower investment in

241 terrestrial locomotor performance in benefit of reproductive output.

242 Morphological determinants of jumping performance

243 Our analyses suggest that peak resultant force is principally determined by hind

244 limb with animals with longer hind limbs generating larger forces in correspondence

245 with previous studies (Nauwelaerts, Ramsay \& Aerts, 2007). While hind limb length

246 was also the best predictor of the peak resultant force for females, ilium length and

247 the length of the longest toe were retained for males. Males with longer ilia, yet

248 shorter longest toes produced greater forces. That the length of the ilium was

249 retained in the model suggest that a caudopelvic mechanism (Jenkins \& Shubin,

250 1998) may be operational in aquatic frogs like $X$. tropicalis. Although previous

251 authors have suggested that in aquatic frogs, pelvic sliding may play an important

252 role in augmenting propulsion during swimming (Videler \& Jorna, 1985), our data

253 suggest that this may play a more important role during jumping than swimming. As

254 the coccygeo-sacralis, the coccygeo-iliacus, and the longissumus dorsi muscles all

255 span the joint between the vertebral column and the pelvic girdle, they may help

256 extend the iliosacral joint. This, in turn, may transfer force to the other joints of the

257 limb and help increase the peak resultant forces (e.g. Aerts, 1998). 
258 Peak vertical forces, in contrast, were best predicted by tibia length for the entire 259 data set. However, in males, ilium length and toe length were the best predictors, 260 while in females, body mass was the best predictor of peak vertical force. The peak 261 forces in the horizontal plane, on the other hand, were best predicted by foot length 262 for the overall data set, by ilium width in males, and by foot length in females. In 263 contrast to the resultant forces, peak forces in the vertical and horizontal planes are 264 determined by different anatomical features when considering males, females and 265 the overall data set. Although this result may be indicative of real differences 266 between the sexes in the morphological traits that determine jumping performance, 267 further experiments involving simultaneous high-speed video and force recordings 268 are needed to better understand why this is the case. For example, differences in 269 jump angle or the contribution of the forelimb in changing body posture before the 270 onset of the jump may all play a role in determining what variables determine peak

271 force. Clearly, only part of the variation in jump force was explained by external

272 morphology with between 15 and $52 \%$ of the overall variation in jump force

273 explained. Thus it would be of interest to explore differences in the limb muscles and 274 their physiological properties as it is known that these play an important role in 275 determining jumping ability in a variety of vertebrate species, including frogs (e.g. 276 Aerts, 1998; Harris \& Steudel, 2002; Toro, Irschick \& Herrel, 2004; James, Navas \& 277 Herrel, 2007; Nauwelaerts, Ramsay \& Aerts, 2007). Specifically, differences in 278 muscle cross sectional area or in muscle fiber type may be important in explaining 279 inter-individual as well as inter-sexual differences in jumping capacity (James et al., 280 2005). For example, significant differences in muscle size and physiology have been 281 noted between the sexes in the forearm muscles in explosive breeders where males 282 compete to gain hold of females (Navas \& James, 2007). Although such mating 283 competition has never been described for $X$. tropicalis sex-dependent differences in 284 muscle physiology may exist and would be of interest to explore further.

\section{Trade-offs in locomotor performance}

286 In the overall data set, no performance trade-offs were detected. Rather, forces were 287 positively correlated to the distance jumped to exhaustion. This result is expected if 288 the energetic of jumping likely limit the number of jumps rather than the actual 289 jump distance given the potential role for energy storage and amplification in 290 jumping in frogs (Lutz \& Rome, 1994; Astley \& Roberts, 2012). Thus a more forceful 291 jump will result in a greater jump distance if jump angle remains unaffected (Marsh, 
292 1994) and thus jump forces should be correlated to total distance jumped until 293 exhaustion. Interestingly, peak horizontal forces were also correlated to peak 294 swimming velocity. Given that swimming involves limb extension in the horizontal 295 plane (Gal \& Blake, 1988; Nauwelaerts et al., 2005; Richards, 2010), the ability of a 296 frog to generate greater forces in the horizontal plane may indeed be logically 297 related to its peak swimming velocity. Previous authors have found no correlation 298 between swimming and jumping ability in a semi-aquatic frog (Nauwelaerts et al., 299 2010). However, these authors investigated only the peak resultant force and did 300 not investigate whether peak forces in the horizontal plane were correlated with 301 peak swimming velocity (Nauwelaerts et al., 2010). Indeed, peak resultant force and 302 swimming speed were not correlated in our dataset either.

303 Data for males were similar to the results for all individuals combined with the 304 exception that no correlation between peak horizontal force and swimming velocity 305 was observed. In females, however, negative relationships between the peak 306 resultant and peak vertical force and the time jumped until exhaustion were 307 observed in addition to the correlation observed for the overall data set. Thus, in 308 females peak jump force trades-off with the time jumped to exhaustion. This 309 suggests that females that produce greater jump forces get tired sooner and stop 310 jumping earlier. As peak resultant and vertical forces are correlated to overall hind 311 limb length and body mass respectively, this suggests that larger females get tired 312 sooner, despite the fact that they can generate larger forces and thus jump further. 313 This is likely due to the differential scaling of force relation to body mass. Indeed 314 whereas body mass increases with hind limb length to the third power, force only 315 increases to the second power (Hill, 1950). Thus larger females have to move a 316 relative larger weight against gravity. In addition, as larger animals tend to rely less 317 on elastic energy storage for jumping (James, Navas \& Herrel, 2007), this suggests a 318 greater energetic cost in animals producing higher forces causing them to tire 319 sooner.

320 In summary, our results show sex-specific differences in jumping performance when 321 correcting for differences in body size. Moreover, the features determining jumping 322 performance are different in the two sexes. Finally, the relationships between 323 different performance traits are sex-dependent with peak jumping force trading-off 324 with the time jumped to exhaustion in females, but not in males. This suggests that 325 different selective pressures may be operating on the two sexes. Females are 
326 subjected to constraints on locomotion due to their greater body mass. Indeed,

327 investment in reproductive output (i.e. large egg mass) causes females to be

328 relatively heavier than males. Males, despite being smaller, are capable of

329 generating the same jump forces as females suggesting that they may have larger

330 limb muscles and/or more fast glycolytic muscle fibers. Thus, males appear to invest

331 more energy in traits related to locomotion giving them a higher locomotor

332 performance for a given body size compared to females. This may be of benefit to

333 males as they are known to disperse in periods of heavy rain to seek mates (Rödel,

334 2000). However, additional studies are needed to better understand the selective

335 pressures operating on males and females in wild populations and how these may

336 influence the evolution of locomotor traits in these frogs.

\section{Acknowledgements}

338 We would like to thank Legrand Nono Gonwouo and Erik Fokam for their valuable

339 help in the field; O. Calvez, J. Rodriguez, N. Bonneau, and P. Provini for helping to

340 take care of the frogs, and M. Antoine for logistical help.

\section{References}

342 Aerts P. 1998. Vertical jumping in Galago senegalensis: the quest for an obligate 343 mechanical power amplifier. Philosophical Transactions of the Royal Society, London 344 353:1607-1620.

345 Arnold SJ. 1992. Constraints on phenotypic evolution. American Naturalist 140:85346107.

347 Astley HC, Roberts TJ. 2011. Evidence for a vertebrate catapult: elastic enegy

348 storage in the plantaris tendon during frog jumping. Biology Letters 8:386-389.

349 Careau V, Biro P, Bonneaud C, Fokam E, Herrel A. 2014. Individual variation in 350 thermal performance curves: swimming burst speed and jumping endurance in wild351 caught tropical clawed frogs. Oecologia 175:471-480.

352 Casterlin ME, Reynolds WW. 1980. Diel activity and thermoregulation behavior of a 353 fully aquatic frog: Xenopus laevis. Hydrobiologia 75:189-191. 
354 Gomes FR, Rezende EL, Grizante MB, Navas CA. 2009. The evolution of jumping 355 performance in anurans: morphological correlates and ecological implications. 356 Journal of Evolutionary Biology 22:1088-1097.

357 Halliday TR, Verrell PR. 1986. Review: sexual selection and body size in amphibians. 358 Herpetological Journal 1:86-92.

359 Harris MA, Steudel K. 2002. The relationships between maximal jumping 360 performance and hind limb morphology/physiology in domestic cats (Felis silvestris 361 catus). Journal of Experimental Biology 205:3877-3889.

362 Herrel A, Bonneaud C. 2012a. Temperature dependence of locomotor performance in 363 the tropical clawed frog, Xenopus tropicalis. Journal of Experimental Biology 364 215:2465-2470.

365 Herrel A, Bonneaud C. 2012b. Trade-offs between burst performance and maximal 366 exertion capacity in a wild amphibian, Xenopus tropicalis. Journal of Experimental 367 Biology 215:3106-3111.

368 Herrel A, Gonwouo LN, Fokam EB, Ngundu WI, Bonneaud C. 2012. Inter-sexual 369 differences in body shape and locomotor performance in the aquatic frog, Xenopus 370 tropicalis. Journal of Zoology 287:311-316.

371 Hill AV. 1950. The dimensions of animals and their muscular dynamics. Science 372 Progress Series 38:209-230.

373 James RS, Wilson RS, Carvalho JE, Kohlsdorf T, Gomes FR, Navas CA. 2005. Inter374 individual differences in leg muscle mass and pyruvate kinase activity correlate with 375 inter-individual differences in jumping performance of Hyla multilineata.

376 Physiological and Biochemical Zoology 78:857-867.

377 James R, Navas C, Herrel A. 2007. How important are skeletal muscle mechanics in 378 setting limits on jumping performance? Journal of Experimental Biology 210:923379933.

380 Marsh RL. 1994. Jumping ability of anuran amphibians. In Jones JH, ed. Advances in 381 veterinary science and comparative medicine. New York: Academic Press, 51-111. 
382 Miller K. 1982. Effect of temperature on sprint performance in the frog Xenopus 383 laevis and the salamander Necturus maculosus. Copeia 1982:695-698.

384 Nauwelaerts S, Aerts P. 2006. Take-off and landing forces in jumping frogs. Journal of 385 Experimental Biology 209:66-77.

386 Nauwelaerts S, Ramsay J, Aerts P. 2007. Morphological correlates of aquatic and 387 terrestrial locomotion in a semi-aquatic frog, Rana esculenta: no evidence for a 388 design conflict. Journal of Anatomy 210:304-317.

389 Navas CA, James RS. 2007. Sexual dimorphism of extensor carpi radialis muscle size, 390 isometric force, relaxation rate and stamina during the breeding season of the frog 391 Rana temporaria Linnaeus 1758. Journal of Experimental Biology 210:715-721.

392 Rödel MO. 2000. Herpetofauna of West Africa. Amphibians of the Western Savannah. 393 Vol. 1. Frankfurt am Main, Germany: Chimaira Buchhandelsgesellschaft mbH.

394 Schauble CS. 2004. Variation in body size and sexual dimorphism across 395 geographical and environmental space in the frogs Limnodynastes tasmaniensis and 396 L. peronii. Biological Journal of the Linnean Society 82:39-56.

397 Shine R. 1979. Sexual selection and sexual dimorphism in the Amphibia. Copeia 398 1979:297-306.

399 Toro E, Herrel A, Irschick DJ. 2004. The evolution of jumping performance in 400 Caribbean Anolis lizards: resolution of a biomechanical trade-off? American 401 Naturalist 163:844-856.

402 Videler JJ, Jorna JT. 1985. Function of the sliding pelvis in Xenopus laevis. Copeia 403 1985:254-257.

404 Videlier M, Bonneaud C, Cornette R, Herrel A. in press. Exploration syndromes in the 405 frog Xenopus (Silurana) tropicalis, correlations with morphology and performance? 406 Journal of Zoology

407 Zug GR. 1972. Anuran locomotion: structure and function I. preliminary observations 408 on the relation between jumping and osteometrics of appendicular and postaxial 409 skeleton. Copeia 1972:613-624. 
410 Zug GR. 1978. Anuran locomotion: structure and function 2. Jumping performance of

411 semiaquatic, terrestrial, and arboreal frogs. Smithsonian Contribution in Zoology

412 276: 1-31.

\section{Figure legends}

414 Figure 1: Example force trace from a female $X$. tropicalis jumping. Indicated are the $415 \mathrm{Z}$ (vertical), $X$ (short axis of the force plate) and $Y$ (long axis of the force plate)

416 forces. Note that the animal is not always positioned in line with the long axis of the

417 force plate, and that horizontal forces cannot be interpreted in terms of fore-aft or

418 medio-lateral forces. When the animal is placed on the force plate the Z-force

419 increases as a result of the weight of the animal as indicated in the figure. Jumping

420 is characterized by a rapid increase in the vertical, as well as in the horizontal

421 forces.

422 Figure 2: Scatter plots illustrating the relationships between morphology and the 423 peak resultant force for female (A) and male (B) frogs. While hind limb length is the 424 best predictor of jump force in females, the length of the ilium is the best predictor 425 in males $(r=0.467 ; P<0.001$; see Table 1$)$. Thus females with longer legs and 426 males with longer ilia are better jumpers $(r=0.717 ; P<0.001$; see Table 1$)$. Each 427 symbol represents the single best jump for an individual. Open symbols represent 428 females, filled symbols represent males.

429 Figure 3: Scatter plot illustrating the differences in the resultant jump force for a 430 given body mass. Note that males (intercept $=-0.78$; slope $=0.66 ; R^{2}=0.15 ; P=$ 4310.003 ) are better jumpers than females (intercept $=-1.05$; slope $=0.88 ; R^{2}=0.50$; $432 P<0.001$ ) for their size (Table 1 ). Each symbol represents the single best jump for 433 an individual. Open symbols represent females, filled symbols represent males.

434 Figure 4: Scatter plots illustrating the relationships between jumping force and 435 endurance capacity. Whereas the distance jumped until exhaustion is positively 436 correlated with jump force in both sexes, the time jumped until exhaustion is 437 positively correlated in males but negatively correlated to peak jump force in 438 females (see Table 2). Each symbol represents the single best jump for an individual. 439 Open symbols represent females, filled symbols represent males. 


\section{Table $\mathbf{1}$ (on next page)}

Table 1: Pearson correlations between jump forces and morphological traits.

Each time the single highest correlation is indicated in bold. SVL, snout-vent length. 
Table 1: Pearson correlations between jump forces and morphological traits.

\begin{tabular}{|c|c|c|c|c|c|c|c|c|c|}
\hline & $\begin{array}{l}\text { SVL } \\
(\mathrm{mm})\end{array}$ & Mass (g) & $\begin{array}{l}\text { Femur } \\
(\mathrm{mm})\end{array}$ & $\begin{array}{l}\text { Tibia } \\
\text { (mm) }\end{array}$ & $\begin{array}{l}\text { Foot } \\
(\mathrm{mm})\end{array}$ & $\begin{array}{l}\text { Toe } \\
(\mathrm{mm})\end{array}$ & $\begin{array}{l}\text { Hind } \\
\text { limb } \\
(m m)\end{array}$ & $\begin{array}{l}\text { Ilium } \\
\text { length } \\
\text { (mm) }\end{array}$ & $\begin{array}{l}\text { Ilium } \\
\text { width } \\
\text { (mm) }\end{array}$ \\
\hline \multicolumn{10}{|c|}{ all individuals $(N=125)$} \\
\hline $\begin{array}{l}\text { Resultan } \\
\text { t force } \\
\text { (N) }\end{array}$ & $\begin{array}{l}r= \\
0.593 \\
P< \\
0.001\end{array}$ & $\begin{array}{l}r= \\
0.594 \\
P< \\
0.001\end{array}$ & $\begin{array}{l}r= \\
0.590 \\
P< \\
0.001\end{array}$ & $\begin{array}{l}r= \\
0.613 \\
P< \\
0.001\end{array}$ & $\begin{array}{l}r= \\
0.605 \\
P< \\
0.001\end{array}$ & $\begin{array}{l}r= \\
0.584 \\
P< \\
0.001\end{array}$ & $\begin{array}{l}r= \\
0.616 \\
P< \\
0.001\end{array}$ & $\begin{array}{l}r=0.586 \\
P<0.001\end{array}$ & $\begin{array}{l}r=0.501 \\
P<0.001\end{array}$ \\
\hline $\begin{array}{l}\text { Vertical } \\
\text { force }(\mathrm{N})\end{array}$ & $\begin{array}{l}r= \\
0.609 \\
P< \\
0.001\end{array}$ & $\begin{array}{l}r= \\
0.599 \\
P< \\
0.001\end{array}$ & $\begin{array}{l}r= \\
0.593 \\
P< \\
0.001\end{array}$ & $\begin{array}{l}r= \\
\mathbf{0 . 6 2 9} \\
P< \\
0.001\end{array}$ & $\begin{array}{l}r= \\
0.602 \\
P< \\
0.001\end{array}$ & $\begin{array}{l}r= \\
0.545 \\
P< \\
0.001\end{array}$ & $\begin{array}{l}r= \\
0.620 \\
P< \\
0.001\end{array}$ & $\begin{array}{l}r=0.592 \\
P<0.001\end{array}$ & $\begin{array}{l}r=0.519 \\
P<0.001\end{array}$ \\
\hline $\begin{array}{l}\text { Horizont } \\
\text { al force } \\
(\mathrm{N})\end{array}$ & $\begin{array}{l}r= \\
0.466 \\
P< \\
0.001\end{array}$ & $\begin{array}{l}r= \\
0.493 \\
P< \\
0.001\end{array}$ & $\begin{array}{l}r= \\
0.469 \\
P< \\
0.001\end{array}$ & $\begin{array}{l}r= \\
0.499 \\
P< \\
0.001\end{array}$ & $\begin{array}{l}r= \\
\mathbf{0 . 5 0 8} \\
P< \\
0.001\end{array}$ & $\begin{array}{l}r= \\
0.442 \\
P< \\
0.001\end{array}$ & $\begin{array}{l}r= \\
0.501 \\
P< \\
0.001\end{array}$ & $\begin{array}{l}r=0.491 \\
P<0.001\end{array}$ & $\begin{array}{l}r=0.448 \\
P<0.001\end{array}$ \\
\hline \multicolumn{10}{|c|}{ males $(N=56)$} \\
\hline $\begin{array}{l}\text { Resultan } \\
\text { t force } \\
\text { (N) }\end{array}$ & $\begin{array}{l}r= \\
0.377 \\
P= \\
0.004\end{array}$ & $\begin{array}{l}r= \\
0.389 \\
P= \\
0.003\end{array}$ & $\begin{array}{l}r= \\
0.220 \\
P= \\
0.103\end{array}$ & $\begin{array}{l}r= \\
0.333 \\
P= \\
0.012\end{array}$ & $\begin{array}{l}r= \\
0.378 \\
P= \\
0.004\end{array}$ & $\begin{array}{l}r= \\
0.114 \\
P= \\
0.404\end{array}$ & $\begin{array}{l}r= \\
0.284 \\
P= \\
0.034\end{array}$ & $\begin{array}{l}\mathbf{r}=\mathbf{0 . 4 6 7} \\
P<0.001\end{array}$ & $\begin{array}{l}r=0.306 \\
P=0.022\end{array}$ \\
\hline $\begin{array}{l}\text { Vertical } \\
\text { force }(\mathrm{N})\end{array}$ & $\begin{array}{l}r= \\
0.459 \\
P< \\
0.001\end{array}$ & $\begin{array}{l}r= \\
0.431 \\
P= \\
0.001\end{array}$ & $\begin{array}{l}r= \\
0.268 \\
P= \\
0.046\end{array}$ & $\begin{array}{l}r= \\
0.421 \\
P= \\
0.001\end{array}$ & $\begin{array}{l}r= \\
0.395 \\
P= \\
0.003\end{array}$ & $\begin{array}{l}r= \\
0.142 \\
P= \\
0.295\end{array}$ & $\begin{array}{l}r= \\
0.337 \\
P= \\
0.011\end{array}$ & $\begin{array}{l}\mathbf{r}=\mathbf{0 . 4 9 7} \\
P<0.001\end{array}$ & $\begin{array}{l}r=0.276 \\
P=0.039\end{array}$ \\
\hline $\begin{array}{l}\text { Horizont } \\
\text { al force } \\
(\mathrm{N})\end{array}$ & $\begin{array}{l}r= \\
0.125 \\
P=359\end{array}$ & $\begin{array}{l}r= \\
0.218 \\
P= \\
0.106\end{array}$ & $\begin{array}{l}r= \\
0.225 \\
P= \\
0.095\end{array}$ & $\begin{array}{l}r= \\
0.219 \\
P= \\
0.104\end{array}$ & $\begin{array}{l}r= \\
0.251 \\
P= \\
0.062\end{array}$ & $\begin{array}{l}r= \\
0.147 \\
P= \\
0.279\end{array}$ & $\begin{array}{l}r= \\
0.232 \\
P= \\
0.086\end{array}$ & $\begin{array}{l}r=0.209 \\
P=0.122\end{array}$ & $\begin{array}{l}\mathbf{r}=\mathbf{0 . 3 9 1} \\
P=0.003\end{array}$ \\
\hline \multicolumn{10}{|c|}{ females $(N=69)$} \\
\hline $\begin{array}{l}\text { Resultan } \\
\text { t force } \\
\text { (N) }\end{array}$ & $\begin{array}{l}r= \\
0.694 \\
P< \\
0.001\end{array}$ & $\begin{array}{l}r= \\
0.707 \\
P< \\
0.001\end{array}$ & $\begin{array}{l}r= \\
0.693 \\
P< \\
0.001\end{array}$ & $\begin{array}{l}r= \\
0.710 \\
P< \\
0.001\end{array}$ & $\begin{array}{l}r= \\
0.690 \\
P< \\
0.001\end{array}$ & $\begin{array}{l}r= \\
0.674 \\
P< \\
0.001\end{array}$ & $\begin{array}{l}r= \\
0.717 \\
P< \\
0.001\end{array}$ & $\begin{array}{l}r=0.673 \\
P<0.001\end{array}$ & $\begin{array}{l}r=0.601 \\
P<0.001\end{array}$ \\
\hline
\end{tabular}




\begin{tabular}{|l|l|l|l|l|l|l|l|l|l|}
\hline Vertical & $\mathrm{r}=$ & $\mathbf{r}=$ & $\mathrm{r}=$ & $\mathrm{r}=$ & $\mathrm{r}=$ & $\mathrm{r}=$ & $\mathrm{r}=$ & $\mathrm{r}=0.688$ & $\mathrm{r}=0.648$ \\
force $(\mathrm{N})$ & 0.711 & $\mathbf{0 . 7 2 1}$ & 0.696 & 0.720 & 0.692 & 0.671 & 0.720 & $\mathrm{P}<0.001$ & $\mathrm{P}<0.001$ \\
& $\mathrm{P}<$ & $\mathrm{P}<$ & $\mathrm{P}<$ & $\mathrm{P}<$ & $\mathrm{P}<$ & $\mathrm{P}<$ & $\mathrm{P}<$ & & \\
& 0.001 & 0.001 & 0.001 & 0.001 & 0.001 & 0.001 & 0.001 & & \\
\hline Horizont & $\mathrm{r}=$ & $\mathrm{r}=$ & $\mathrm{r}=$ & $\mathrm{r}=$ & $\mathbf{r}=$ & $\mathrm{r}=$ & $\mathrm{r}=$ & $\mathrm{r}=0.549$ & $\mathrm{r}=0.443$ \\
al force & 0.536 & 0.552 & 0.520 & 0.563 & $\mathbf{0 . 5 6 9}$ & 0.518 & 0.560 & $\mathrm{P}<0.001$ & $\mathrm{P}<0.001$ \\
(N) & $\mathrm{P}<$ & $\mathrm{P}<$ & $\mathrm{P}<$ & $\mathrm{P}<$ & $\mathrm{P}<$ & $\mathrm{P}<$ & $\mathrm{P}<$ & & \\
& 0.001 & 0.001 & 0.001 & 0.001 & 0.001 & 0.001 & 0.001 & & \\
\hline
\end{tabular}

Each time the single highest correlation is indicated in bold. SVL, snout-vent length. 
Table 2 (on next page)

Table 2: Pearson correlations among performance traits.

Bolded values represent significant correlations. 
Table 2: Pearson correlations among performance traits.

\begin{tabular}{|c|c|c|c|c|}
\hline & $\begin{array}{l}\text { Max. speed } \\
\left(\mathrm{m} \cdot \mathrm{s}^{-1}\right)\end{array}$ & $\begin{array}{l}\text { Max acceleration } \\
\left(\mathrm{m} . \mathrm{s}^{-2}\right)\end{array}$ & $\begin{array}{l}\text { Time to } \\
\text { exhaustion (s) }\end{array}$ & $\begin{array}{l}\text { Distance to } \\
\text { exhaustion }(\mathrm{cm})\end{array}$ \\
\hline \multicolumn{5}{|c|}{ all individuals $(N=125)$} \\
\hline Resultant force $(\mathrm{N})$ & $\begin{array}{l}r=0.056 \\
P=0.538\end{array}$ & $\begin{array}{l}r=-0.008 \\
P=0.925\end{array}$ & $\begin{array}{l}r=-0.112 \\
P=0.215\end{array}$ & $\begin{array}{l}r=\mathbf{0 . 2 6 9} \\
P=0.003\end{array}$ \\
\hline Vertical force $(\mathrm{N})$ & $\begin{array}{l}r=0.017 \\
P=0.849\end{array}$ & $\begin{array}{l}r=-0.053 \\
P=0.556\end{array}$ & $\begin{array}{l}r=-0.107 \\
P=0.241\end{array}$ & $\begin{array}{l}r=\mathbf{0 . 2 6 5} \\
P=0.003\end{array}$ \\
\hline Horizontal force $(\mathrm{N})$ & $\begin{array}{l}\boldsymbol{r}=\mathbf{0 . 1 7 8} \\
P=0.047\end{array}$ & $\begin{array}{l}r=0.003 \\
P=0.977\end{array}$ & $\begin{array}{l}r=-0.028 \\
P=0.760\end{array}$ & $\begin{array}{l}r=\mathbf{0 . 2 4 1} \\
P=0.007\end{array}$ \\
\hline \multicolumn{5}{|c|}{ males $(N=56)$} \\
\hline Resultant force $(\mathrm{N})$ & $\begin{array}{l}r=-0.220 \\
P=0.104\end{array}$ & $\begin{array}{l}r=-0.125 \\
P=0.357\end{array}$ & $\begin{array}{l}r=0.188 \\
P=0.170\end{array}$ & $\begin{array}{l}\boldsymbol{r}=\mathbf{0 . 3 2 0} \\
P=0.017\end{array}$ \\
\hline Vertical force $(\mathrm{N})$ & $\begin{array}{l}r=-0.188 \\
P=0.165\end{array}$ & $\begin{array}{l}r=-0.181 \\
P=0.183\end{array}$ & $\begin{array}{l}r=0.156 \\
P=0.256\end{array}$ & $\begin{array}{l}r=\mathbf{0 . 3 4 6} \\
P=0.010\end{array}$ \\
\hline Horizontal force $(\mathrm{N})$ & $\begin{array}{l}r=0.039 \\
P=0.776\end{array}$ & $\begin{array}{l}r=-0.005 \\
P=0.969\end{array}$ & $\begin{array}{l}r=0.192 \\
P=0.161\end{array}$ & $\begin{array}{l}r=0.161 \\
P=0.241\end{array}$ \\
\hline \multicolumn{5}{|c|}{ Females $(\mathrm{N}=)$} \\
\hline Resultant force $(\mathrm{N})$ & $\begin{array}{l}r=0.206 \\
P=0.090\end{array}$ & $\begin{array}{l}r=0.052 \\
P=0.673\end{array}$ & $\begin{array}{l}r=\mathbf{- 0 . 2 6 3} \\
P=0.030\end{array}$ & $\begin{array}{l}r=\mathbf{0 . 2 7 3} \\
P=0.024\end{array}$ \\
\hline Vertical force $(\mathrm{N})$ & $\begin{array}{l}r=0.135 \\
P=0.270\end{array}$ & $\begin{array}{l}r=0.016 \\
P=0.893\end{array}$ & $\begin{array}{l}r=-\mathbf{0 . 2 4 3} \\
P=0.046\end{array}$ & $\begin{array}{l}r=\mathbf{0 . 2 4 6} \\
P=0.043\end{array}$ \\
\hline Horizontal force $(\mathrm{N})$ & $\begin{array}{l}r=\mathbf{0 . 2 4 2} \\
P=0.045\end{array}$ & $\begin{array}{l}r=-0.028 \\
P=0.817\end{array}$ & $\begin{array}{l}r=-0.147 \\
P=0.230\end{array}$ & $\begin{array}{l}r=\mathbf{0 . 3 4 4} \\
P=0.004\end{array}$ \\
\hline
\end{tabular}

Bolded values represent significant correlations. 


\section{Figure 1}

Example force trace from a female $X$. tropicalis jumping.

Indicated are the $Z$ (vertical), $X$ (short axis of the force plate) and $Y$ (long axis of the force plate) forces. Note that the animal is not always positioned in line with the long axis of the force plate, and that horizontal forces cannot be interpreted in terms of fore-aft or mediolateral forces. When the animal is placed on the force plate the Z-force increases as a result of the weight of the animal as indicated in the figure. Jumping is characterized by a rapid increase in the vertical, as well as in the horizontal forces.

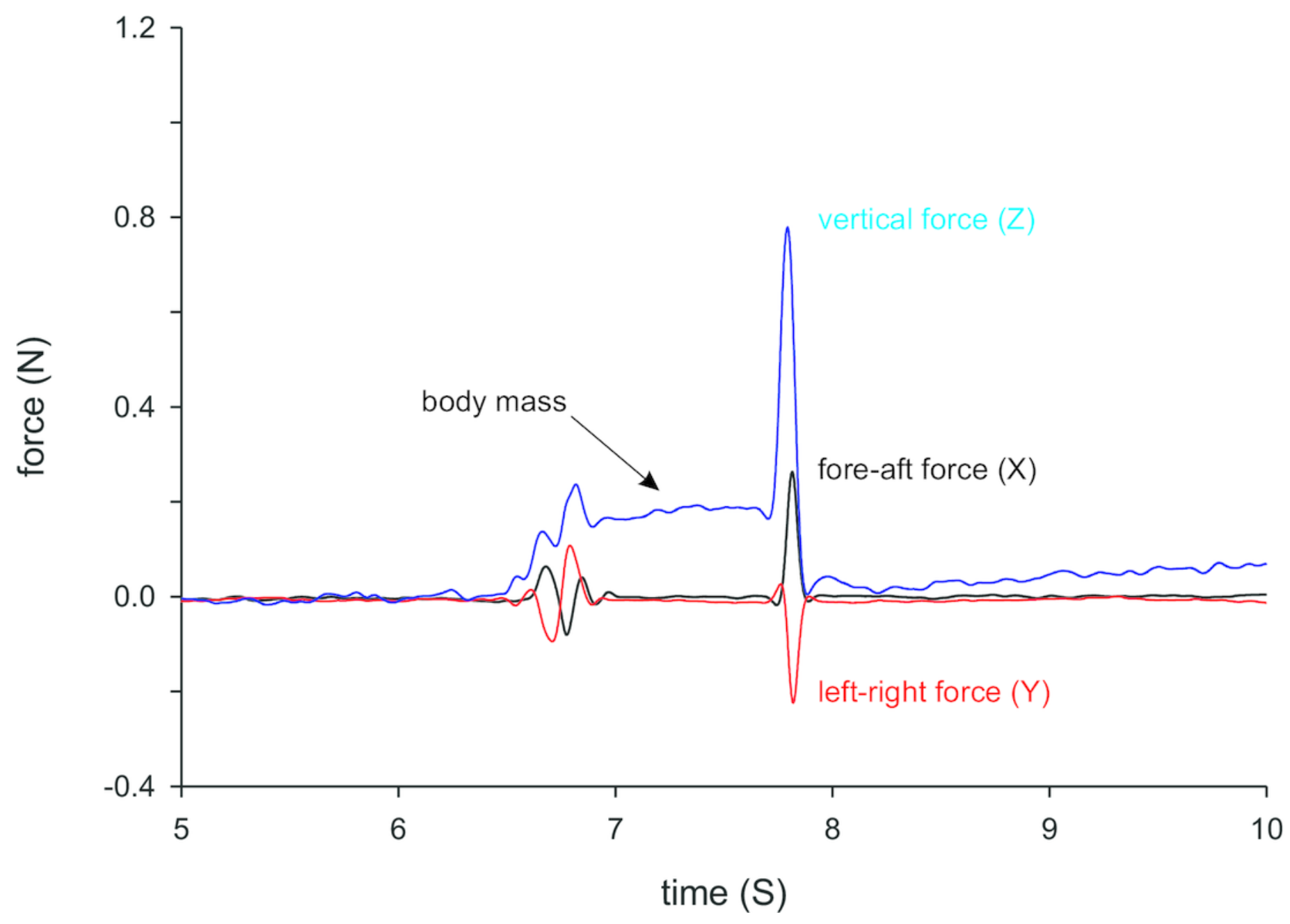




\section{Figure 2}

Scatter plots illustrating the relationships between morphology and the peak resultant force.

Scatter plots illustrating the relationships between morphology and the peak resultant force for female (A) and male (B) frogs. While hind limb length is the best predictor of jump force in females, the length of the ilium is the best predictor in males $(r=0.467 ; P<0.001$; see Table 1). Thus females with longer legs and males with longer ilia are better jumpers ( $r=$ $0.717 ; P<0.001$; see Table 1 ). Each symbol represents the single best jump for an individual. Open symbols represent females, filled symbols represent males. 

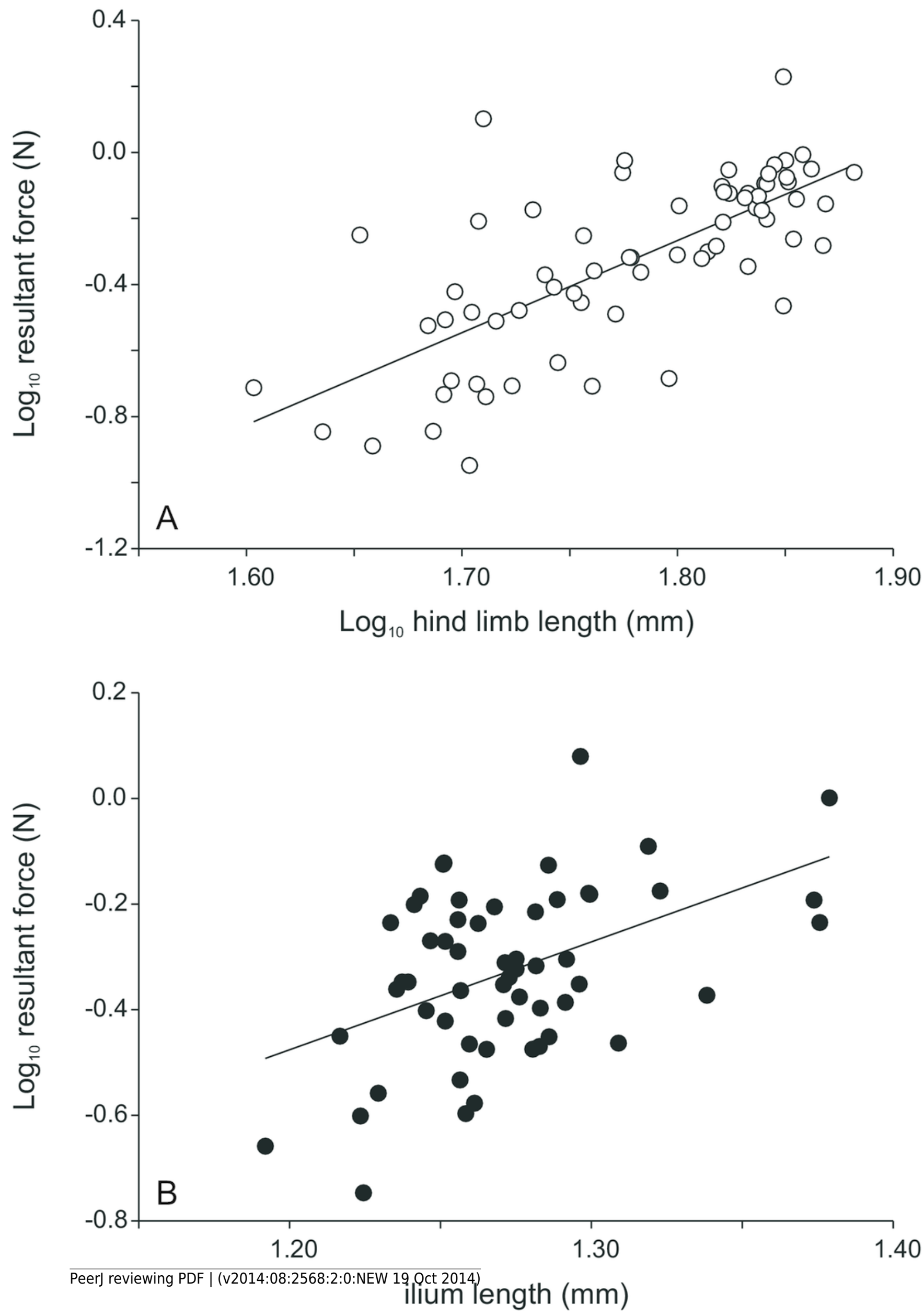
Figure 3

Scatter plot illustrating the differences in the resultant jump force for a given body mass.

Note that males (intercept $=-0.78$; slope $=0.66 ; R^{2}=0.15 ; P=0.003$ ) are better jumpers than females (intercept $=-1.05$; slope $=0.88 ; R^{2}=0.50 ; P<0.001$ ) for their size (Table 1 ). Each symbol represents the single best jump for an individual. Open symbols represent females, filled symbols represent males.

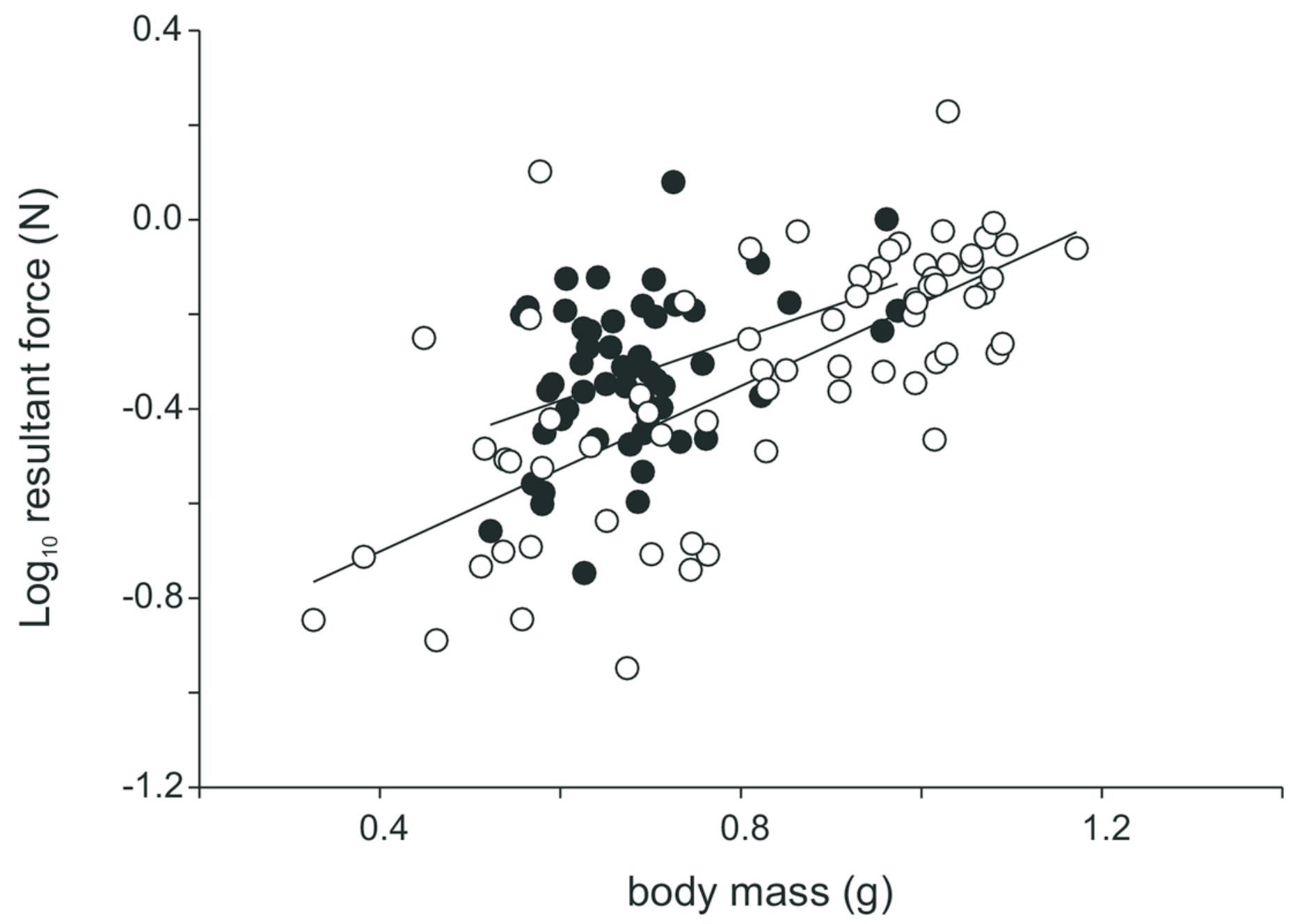


Figure 4

Scatter plots illustrating the relationships between jumping force and endurance capacity.

Whereas the distance jumped until exhaustion is positively correlated with jump force in both sexes, the time jumped until exhaustion is positively correlated in males but negatively correlated to peak jump force in females (see Table 2). Each symbol represents the single best jump for an individual. Open symbols represent females, filled symbols represent males. 

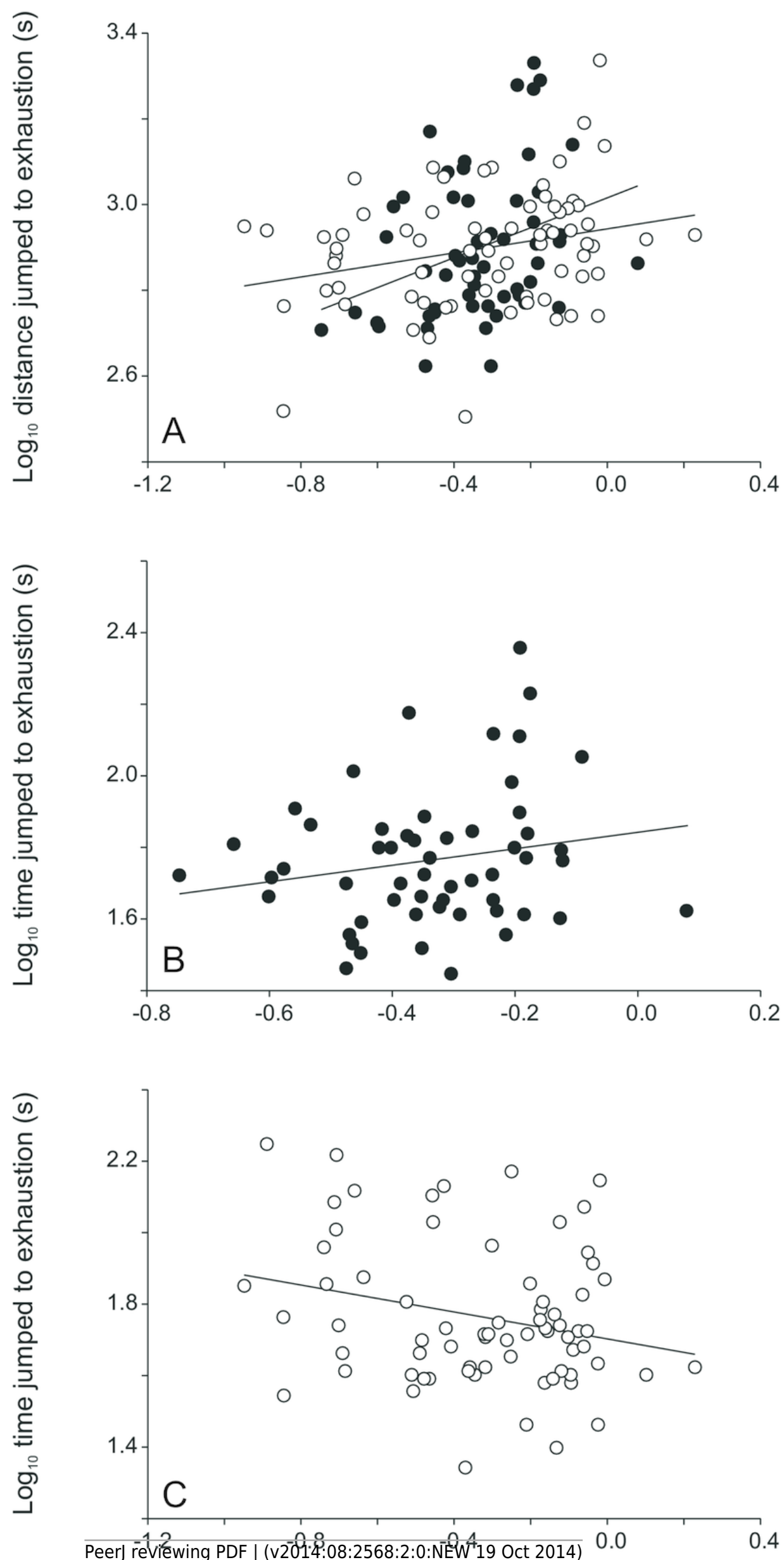

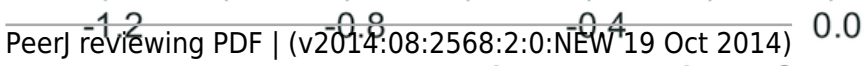

